\title{
Randomized Control Trial of IVIG as An Adjuvant in the Treatment of Preterm and or Low Birth Weight Neonatal Sepsis
}

\author{
Sekar M .N ${ }^{1}$, Anjan Kumar VS *2, Ravi Kumar P ${ }^{3}$, Siva Ramudu K ${ }^{4}$, Mallikarjuna M ${ }^{5}$, \\ Sasi Kumar B ${ }^{6}$, \\ 1,2,4,5,6Assistant Professor, Department of Pediatrics, Sri Venkateswara Medical College, Tirupati, \\ Andhra Pradesh, India. \\ ${ }^{3}$ Professor and Head, Department of Pediatrics, Sri Venkateswara M edical College, Tirupati, Andhra \\ Pradesh, India.
}

\section{ABSTRACT}

Introduction: In developing countries neonatal sepsis ranks as most common illness responsible for neonatal mortality especially in low birth weight and preterm babies. In India, it is responsible for $25-50 \%$ of neonatal deaths in spite of early diagnosis and treatment. There have been many trials on various adjuvant therapies (like leuko cyte transfer, GCSF, GM CSF, fibronectin, IVIG, FFP) in addition to specific antimicrobial therapy. There is still some controversy in the role of IVIG in treatment of neonatal sepsis. Hence the study was undertaken to evaluate the efficacy of IVIG in treatment of neonatal sepsis.

Materials and M ethods: 30 in group total 60 babies with gestation $\leq 32$ wks and wt $\leq 2000$ gm were enrolled in the study if they had one or more clinical features of sepsis and had elevated C-reactive protein ( $>10 \mathrm{mg} / \mathrm{dl})$. Babies in both groups underwent investigations including micro ESR, WBC count, ANC, Platelet count, LFT, Blood culture \& Urine culture. In IVIG group samples were drawn before giving IVIG.

Results: There is no significant decrease in mortality, severity of illness and duration of hospital stay in IVIG group than control group.

Conclusions: As of other studies, our study also did not show any significant role of IVIG as an adjuvant in the treatment of sepsis in preterm or low birth weight neonates.

KEY WORDS: Leukocyte transfer, GCSF, GM CSF, Fibronectin, IVIG and FFP.

Address for correspondence: Dr. V.S.Anjan Kumar MD, Assistant Professor, Department of Pediatrics, Sri Venkateswara M edical College, Tirupati, Andhra Pradesh, India.

E-Mail: dr.anjankumar@gmail.com

\begin{tabular}{|c|c|c|}
\hline \multicolumn{3}{|c|}{ Online Access and Article Informtaion } \\
\hline \multirow{2}{*}{$\begin{array}{l}\text { Quick Response code } \\
\text { Dol: } 10.16965 \text { /jims.2015.115 }\end{array}$} & \multicolumn{2}{|c|}{$\begin{array}{c}\text { International Journal of Integrative Medical Sciences } \\
\text { www.imedsciences.com }\end{array}$} \\
\hline & $\begin{array}{l}\text { Received: 24-04-2015 } \\
\text { Review: 24-04-2015 }\end{array}$ & $\begin{array}{l}\text { Accepted: 21-05-2015 } \\
\text { Published: 31-05-2015 }\end{array}$ \\
\hline Source of Funding: Self & \multicolumn{2}{|c|}{ Conflicts of interest: None } \\
\hline
\end{tabular}

\section{INTRODUCTION}

The neonatal septicemia is Presence of generalized systemic features of sepsis associated with pure growth of bacteria from more than one site [1]. In developing countries neonatal sepsis ranks as most common illness responsible for neonatal mortality especially in low birth weight and preterm babies [2]. In India, it is responsible for nearly $1 / 4-1 / 2$ of neonatal deaths. Neonatal septicemia has a high case fatality rate if it is not recognized early and treated promptly. Theoretically, it is possible to treat neonatal sepsis successfully with presently available antimicrobial agents if recognized in early stages. Low birth weight, small for gestational age and preterm babies are very vulnerable to sepsis because of compromised immunity in the form of deficient immunoglobulin, complement and phagocytic capability [2] and also due to iatrogenic factors like exten- 
-sive handling resulting in breaks in mucosal and skin barriers [1]. Blood stream infections have been quoted as the most common infections in the neonates.

The incidence varies with a number of factors like prematurity, low birth weight, intrauterine growth retardation, sex [1] and overcrowding of neonatal units, hospitals or community. Incidence of sepsis varies in various settings like community, tertiary care center (NICU) and In the community according to a study by Abhay Bang at Ghadchiroli, 36 villages with a population of 36,613 had $65 \%$ incidence of neonatal sepsis that was detected based on clinical suspicion. In hospital situations in India according to national neonatal and perinatal data 1995, which is based on 17 different centers, the incidence of neonatal sepsis was $3.8 \%$ in all live births [3]. Neonatal sepsis among term babies is $36 \%$ and $64 \%$ in preterm's [4]. Incidence of sepsis according to birth weight is 401 - $750 \mathrm{gm}-43 \%, 751$ - $1000 \mathrm{gm}-28 \%, 1001$ - $1250 \mathrm{gm}-15 \%, 1251$ - $1500 \mathrm{gm}-7 \%$. In developing countries the incidence of late onset sepsis is $<1000 \mathrm{gm}-46.4 \%$, $<1249 \mathrm{gm}-30.6 \%$, $<1500 \mathrm{gm}-16.8 \%$. The incidence of neonatal sepsis in India is 9.8 per 1000 live births [4].

\section{In developing countries like India incidence is high due to various reasons like:}

1. A majority of the newborns are low birth weight and premature ( $33 \%$ of live births weigh $<2.5 \mathrm{~kg}$ ) [5]

2. Most of the deliveries are done at home by untrained dais [6]

3. During the delivery the dais will not maintain aseptic precautions (5 cleans viz clean hands, clean surface, clean cord, clean blade and clean cord tie).

4. Traditional practices like : $[6,7]$

a) Giving prelacteal feeds.

b) Application of cow dung over the cord.

c) Delayed initiation of breast feeds and not giving colostrum

5. Overcrowding of NICU and understaffing may lead to increased rate of cross infections [8].

6. The infection control measures are not properly followed due to inadequate resources [8].
The Neonatal sepsis is associated with morbidities like seizures (meningitis), apnea, respiratory distress syndrome (pneumonia), and neonatal jaundice, necrotizing enterocolitis, hypothermia, hyperthermia, hypoglycemia, hyperglycemia and metabolic acidosis. M ortality due to sepsis is inversely related to birth weight and gestational age. M ortality with sepsis rates among: <1500 gm - 90\%, 1500 - 2000gm $70 \%, 2001-2500 \mathrm{gm}-63 \%$ and $>2500 \mathrm{gm}-$ $35 \%$. According to gestational age: $<34$ weeks $-78 \%, 35-36$ weeks - $73 \%$, and $>36$ weeks $49 \%$. Other major complications are [9] Sepsis syndrome, Multi organ dysfunction and Septic shock. Neonatal mortality is mainly affected by many factors like early and late onset sepsis, organisms involved, multi organ dysfunction, meningitis, pneumonia, prematurity, low birth weight and associated malformations.

IVIG In Treatment of Neonal Sepsis: In human studies, several small studies have addressed the efficacy of using IVIG for treatment of sepsis [10-14]. Four of five studies [10-14] were prospective with one being retrospective. The dose of IVIG used varied widely with ranges from $500-1000 \mathrm{mg} / \mathrm{kg}$. Combining the results of these studies through a meta-analysis [15], it was concluded that septic neonate treated with IVIG had at least 6 fold lower short term mortality rate than those not receiving IVIG. Other metaanalysis however conclude that insufficient evidence exists to support the routine administration of IVIG to prevent or treat neonatal sepsis. A study by Sunitha Sreedhar \& Anagha Jayakar revealed that they did not find any statistically significant decrease in mortality with use of IVIG irrespective of gestational age and birth weight. They also found that IVIG did not prevent sepsis. Study by Sidroponlos et al [15] showed a significant decrease in mortality in preterm babies. Friedman et al [13] showed no statistically significant difference. A multicentric placebo controlled trial by Weisman [11] showed significant decrease in mortality in $1^{\text {st }} 7$ days, while survival at 56 days had not improved significantly. Because of decreased concentration of IgG in preterm infants, several studies have addressed the use of IVIG as a prophylaxis [12] Kinney et al [17], Fanaroff AA et al [18] found no effect of IVIG in neonatal sepsis 
prevention. Magay et al [19] found that the difference was not statistically significant. Chirico et al [20] suggested that IVIG may be effective as prophylaxis only in VLBW. Many studies $[20,21]$ found that IVIG as prophylaxis significantly reduced the number of infective episodes. In a largest prophylaxis study [17] which involved 2416 neonates in a multicentric, prospective, randomized, placebo controlled study, IVIG given and repeated every 14 days until baby weighed $1300 \mathrm{gms}$ or discharged. Sepsis reported in 208 of 1204 (17\%) in IVIG group and 231 of $1212(19 \%)$ in control group and proved that prophylactic use of IVIG failed to reduce incidence of hospital acquired infection in VLBW infants. The T $1 / 2$ of IVIG is 18 - 23 days in normal individuals; but varies in patients with antibody deficiency [23]. It gets rapidly distributed to the extravascular space with about half the IgG being redistributed to extravascular compartment during first 3-5days after IV infusion. Elimination of IVIG occurs through reticulo endothelial system.

Inspite of early diagnosis and treatment, mortality of neonatal sepsis is still high. There has been many trials on various adjuvant therapies for neonatal sepsis in addition to specific antimicrobial therapy. Among the adjuvant therapies (PRBCS, FFP, leucocyte transfer, GCSF, GM CSF \& fibronectin) IVIG is recommended by many authors as the preterm babies have very low levels of IgG in their blood. But various trials have not come to a conclusion whether IVIG is useful or not. Hence this study has been undertaken to evaluate the role of IVIG in treatment of neonatal sepsis.

\section{MATERIALS AND METHODS}

It's a Randomized controlled trial cared out in the Neonatal Unit, Department of Pediatrics, SVRRGG Hospital, SV M edical College, Tirupati, Andhr pradesh, India. 60 babies were taken in this study and divided in to two groups. 30 babies per group was required to detect a $50 \%$ reduction in mortality with a power of $80 \%$ and an alpha error of $5 \%$. Patients (30) Babies with birth weight $\leq 2000 \mathrm{gms}$ and or gestation $\leq 32$ weeks with one or more clinical features of sepsis and elevated C-reactive protein ( $>10 \mathrm{mg} / \mathrm{Lit}$ ) were enrolled into study after getting informed consent from parents. At enrolment all data were collected regarding: $M$ aternal history, perinatal details, Demographic data, and Clinical features of sepsis. Excluded from the study with severe intracranial haemorrhage, severe cardiac abnormality, severe respiratory distress syndrome, other severe underlying disease. Babies assigned to study group were given a single dose of $500 \mathrm{mg} / \mathrm{kg}$ of IVIG (Gamma IV from Bharat Serum and Vaccines Limited) by infusion over 2 hours. In study group blood samples were drawn before infusing IVIG. Monitoring was done for all babies at 12 hourly intervals during the period of hospitalization.

Investigations: Complete blood picture (Absolute neutrophil count), Platelet count, Creactive protein, Micro ESR, Liver function test, Blood culture, Urine culture investigations were done in all babies at enrolment, on day 10 and at the time of discharge.

Treatment and Follow up: Supportive care and antibiotics were given for all babies, Antibiotics were changed only if there was no clinical improvement in 48 hours after starting antibiotics (or) as per culture sensitivity pattern. Grading of antibiotics was done as follows:

First line antibiotics: Ampicillin, Cefotaxime, Aminoglycosides

Second line antibiotics: Ciprofloxacin, Cloxacillin

Third line antibiotics: Piperacillin, Tazobactum

Fourth line antibiotics:M eropenam, Imipenam, Vancomyicn

All discharged babies were followed up for a period of one month after enrolment to monitor outcome. They were contacted on phone weekly and a follow up visit was arranged at 1 month. M ortality within one month of enrolment was considered as primary outcome. Secondary outcome was Duration of hospitalization, Time for subsidence of clinical features. All the data was analyzed by Chi-square test and Student' $t$ ' test.

\section{RESULTS}

During the study period totally 60 babies were enrolled, 30 babies in each Test Group (IVIG) and Control group. Out of total 60 babies enrolled, 41 (68.33\%) 
babies were less than $1.5 \mathrm{~kg}, 19$ (31.66\%) babies were between 1.5 - $2 \mathrm{~kg}$ were enrolled.

\begin{tabular}{|c|c|c|c|c|}
\hline Variable & IVIG $(n=30$ & Control $(n=30)$ & P value & \multirow{5}{*}{$\begin{array}{l}\text { Table 1: Shows the BASE LINE DATA } \\
\text { of IVIG group and control groups. }\end{array}$} \\
\hline $\begin{array}{l}\text { Gestation in weeks } \\
\text { (MEAN } \pm \text { SD) }\end{array}$ & $30.80 \pm 2.38$ & $30.60 \pm 2.42$ & 0.748 & \\
\hline $\begin{array}{l}\text { Birth Wt in gms } \\
\text { MEAN } \pm S D\end{array}$ & $1393.53 \pm 255.05$ & $1428.30 \pm 258.36$ & 0.602 & \\
\hline$<1.5 \mathrm{~kg}(\%)$ & $22(73.33 \%)$ & $19(63.33 \%)$ & - & \\
\hline 1.5 - 2 kg (\%) & $8(25.66)$ & $11(36.66)$ & - & \\
\hline
\end{tabular}

In Test group, mean weight was 1393. $53 \pm$ 255.05 gms of whom $22(73.33 \%)$ babies were less than $1.5 \mathrm{~kg}, 8(25.66 \%)$ babies were between 1.5 and $2 \mathrm{kgmean}$ gestational age was $30.80 \pm$ 2.38 weeks. In control group, mean weight was $1428.30 \pm 258.36$ gms. 19 (63.33\%) babies were less than $1.5 \mathrm{~kg}$ and11 (36.66\%) babies were between 1.5 and $2 \mathrm{kgs}$. M ean gestational age was $30.6 \pm 2.42$ weeks.

Table 2: Showing the CLINICAL FEATURES OF SEPSIS of IVIG group and control groups.

\begin{tabular}{|c|c|c|}
\hline Signs / Symptoms & VIG (n=30) & Control (n=30) \\
\hline $\begin{array}{c}\text { Age of Onset of Sepsis } \\
\text { (Days +Std deviation) }\end{array}$ & $3.60 \pm 1.98$ & $3.23 \pm 2.19$ \\
\hline Lethargy / ROFS (\%) & $25(83.33)$ & $28(93.33)$ \\
\hline Prolonged CFT (\%) & $9(30.00)$ & $14(46.66)$ \\
\hline Tachycardia (\%) & $12(40.00)$ & $14(46.66)$ \\
\hline Apnea (\%) & $6(20.00)$ & $3(10.00)$ \\
\hline Jaundice (\%) & $17(56.66)$ & $11(36.66)$ \\
\hline Sclerema (\%) & $5(16.66)$ & $7(23.33)$ \\
\hline $\begin{array}{c}\text { Others (RD, Abd dist } \\
\text { bleeding) (\%) }\end{array}$ & $9(30.00)$ & $10(33.33)$ \\
\hline
\end{tabular}

The babies in test group were diagnosed to have sepsis at the average age of $3.60 \pm 1.98$ days. 25 (83.33\%) babies among them had lethargy and refusal of feeds. Jaundice is seen in 17 (56.66\%) babies. Tachycardia and prolonged CFT seen in $12(40.00 \%)$ and $9(30.00 \%)$ babies respectively. Apnea seen in $6(20.00 \%)$ babies and sclerema in $5(16.66 \%)$ babies.

In control group average age of onset of sepsis was $3.23 \pm 2.19$ days.28 (93.33\%) babies had lethargy and refusal of feeds. 14 (46.66\%)babies with prolonged CFT and raised heart rate. Jaundice seen in 11 (36.66\%) babies and sclerema in 7 (23.33\%) babies. Apnea seen in 3 (10.00\%) babies.
Table 3: Shows the INVESTIGATIONS of IVIG group and control groups.

\begin{tabular}{|c|c|c|}
\hline $\begin{array}{c}\text { Investigations At } \\
\text { Enrolment }\end{array}$ & $\begin{array}{c}\text { IVIG } \\
(\mathbf{n}=30)\end{array}$ & $\begin{array}{c}\text { Control } \\
(\mathbf{n}=\mathbf{3 0})\end{array}$ \\
\hline CRP Positivity & 30 & 30 \\
\hline ESR $>\mathbf{1 0 m m} / \mathbf{h r}$ & $21(70 \%)$ & $\begin{array}{c}22 \\
(73.33 \%)\end{array}$ \\
\hline $\mathrm{WBC}<5000 / \mathbf{m m}^{3}$ & $1(3.33 \%)$ & - \\
\hline $\mathrm{WBC}>\mathbf{1 5 0 0 0} / \mathbf{m m}^{3}$ & $9(30 \%)$ & $8(25.66 \%)$ \\
\hline Platelet $<\mathbf{1 , 0 0 , 0 0 0 ( \% )}$ & $3(10 \%)$ & $2(6.66 \%)$ \\
\hline Abnormal LrT (\%) & $4(13.33 \%)$ & $6(20 \%)$ \\
\hline
\end{tabular}

The result are showing in cases and controls that $21(70 \%)$ babies and 22 (73.33\%) babies were with ESR of $>10 \mathrm{~mm}$ respectively. Low WBC count seen in $9(30.00 \%)$ cases and $8(25.66 \%)$ controls. Abnormal LFT found in 4 (13.33\%) in cases and $6(20.00 \%)$ control babies. Thrombocytopenia in $3(10.00 \%)$ cases and $2(6.66 \%)$ in controls.

Table 4: Showing the BLOOD / URINE CULTURES in IVIG group and control group.

\begin{tabular}{|c|c|c|}
\hline Variable & $\begin{array}{c}\text { IVIG } \\
\mathbf{n = 3 0}\end{array}$ & $\begin{array}{c}\text { Control } \\
\mathbf{n = 3 0}\end{array}$ \\
\hline $\begin{array}{c}\text { Blood culture } \\
\text { positivity (\%) }\end{array}$ & $7(23.33)$ & $17(56.66 \%)$ \\
\hline Klebsiella (\%) & $7(23.33)$ & $13(43.33)$ \\
\hline E.coli (\%) & - & $3(10.00)$ \\
\hline Citrobacter (\%) & - & $1(3.33)$ \\
\hline $\begin{array}{c}\text { Urine culture } \\
\text { positivity (\%) }\end{array}$ & $2(6.66)$ & $4(13.33)$ \\
\hline
\end{tabular}

Totally 24 (40.00\%) babies of 60 enrolled, showed culture positivity. In IVIG group 7 (23.33\%) babies found to have culture positivity. All showed klebsiella. In control group 17 (56.66\%) babies showed culture positivity. Klebsiella in 13 (43.33\%), E.coli in $3(10.00 \%)$, Citrobacter in1 (3.33\%). Urine culture was positive in 6 (10.00\%) babies of 60 enrolled. 2 (6.66\%) in test group, 4 (13.33\%) in control group. 
Table 5: Shows the TREATM ENT OF SEPSIS in cases and controls.

\begin{tabular}{|c|c|c|}
\hline Variable & $\begin{array}{c}\text { IVIG } \\
(\mathbf{n = 3 0 )}\end{array}$ & $\begin{array}{c}\text { Control } \\
(\mathbf{n = 3 0 )}\end{array}$ \\
\hline $\begin{array}{c}\text { Step II Antibiotics (\%) } \\
\text { (Ciprofloxacin) }\end{array}$ & $6(20.00)$ & $2(6.66)$ \\
\hline $\begin{array}{c}\text { Step III Antibiotics (\%) } \\
\text { (Piperacillin + Tazobactum) }\end{array}$ & $17(56.66)$ & $15(50.00)$ \\
\hline $\begin{array}{c}\text { Step IV Antibiotics (\%) } \\
\text { (Meropenem) }\end{array}$ & $2(6.66)$ & $2(6.66)$ \\
\hline Inotropes (\%) & $10(33.33)$ & $13(43.33)$ \\
\hline FFP / Blood transfusion (\%) & $3(10.00)$ & - \\
\hline Exchange transfusion (\%) & $3(10.00)$ & $2(6.66)$ \\
\hline
\end{tabular}

Test Group: In this group 6 (20.00\%) babies required ciprofloxacin. 17 (5.66\%) babies were given Piperacillin + Tazobacterm and meropenem in 2 (6.66\%) babies. Inotropes and blood products were given in $10(33.33 \%)$ and 3 $(100 \%)$ babies respectively. Exchange transfusion was done in $3(10.00 \%)$ babies.

Control Group B: Ciprofloxacin in 2 (6.66\%) babies, Piperacillin + Tazobacterm in 15 (50.00\%) babies and meropenem in 2 (6.66\%) babies.Inotropes given in 13 (43.33\%) babies and $2(6.66 \%)$ babies received exchange transfusion.

Table 6: Showing OUTCOME of cases and controls.

\begin{tabular}{|c|c|c|c|}
\hline Outcome & $\begin{array}{c}\text { IVIG } \\
(\mathbf{n = 3 0 )}\end{array}$ & $\begin{array}{c}\text { Control } \\
(\mathbf{n = 3 0 )}\end{array}$ & P- value \\
\hline Mortality in Hospital (\%) & $11(36.66)$ & $13(43.33)$ & 0.297 \\
\hline $\begin{array}{c}\text { Duration of Hospital Stay of } \\
\text { survived in days } \\
\text { (M EAN+SD) }\end{array}$ & $9.81 \pm 4.25$ & $9.92 \pm 3.71$ & 0.345 \\
\hline $\begin{array}{c}\text { Mortality in Hospital no.0f days } \\
\text { after enrol ment in days } \\
\text { (MEAN } \pm S D)\end{array}$ & $4.09 \pm 1.9$ & $4.07 \pm 1.7$ & 0.405 \\
\hline Total Mortality By 30 days (\%) & $14(46.66)$ & $17(56.66)$ & 0.303 \\
\hline
\end{tabular}

In our study totally 31 (51.66\%) babies died within 30 days of enrolment. Test Group:

11 (36.66\%) babies died in hospital and 3 (10.00\%) babies died in home after discharge within 30days of enrolment. Total mortality is $14(46.66 \%)$ babies. Mortality occurred at the average of $4.09+1.9$ days after IVIG.The average duration of hospital stay required in survived babies was $9.81 \pm 4.25$ days. In Control Group total mortality is 17 (56.66\%) babies.13 (43.33\%) babies died in hospital and 4 (13.33\%) babies died after discharge. After enrolment, mortality occurred at an average of $4.07+1.7$ days. Durationof hospital stay was $9.92 \pm 3.71$ days.

\section{DISCUSSION}

Intravenous Immunoglobulins enhances neonatal host defense by providing opsonic antibody against neonatal pathogens that enhance phagocytosis and killing of bacteria by neutrophils. Also helps in neutralizing toxins and immunomodulating $T$ cells and macrophages. Improve B cell formation and Improve function of complement system [24]. In our study though there is $10 \%$ decreased mortality in IVIG group it was not statistically significant. The duration of hospital stay was also unaltered. The severity of illness i.e., the duration from diagnosis of sepsis to death were also similar in both IVIG and control groups. A Western study by Sidiropoules et al in 1986 showed statistically significant decrease in mortality in preterm babies only. In Friedman et al study in 1989, no significant decrease in mortality was seen. Later, the other study by Weisman et al in 1993 also showed significant decrease in mortality in first 7 days but survival at 56 days has not improved significantly. We have compared our study with two other Indian studies, one as a multicentric study conducted in 3 medical colleges including St. Jhon's M edical College, M.S. Ramaiah M edical College and Manipal Hospital in Banglore and one more study from T.N.Medical College, Mumbai.

In Bangalore study, the mortality in IVIG group and the control group were similar i.e., 28\%, whereas in M umbai study the mortality in IVIG group was 39\% against $32.5 \%$ in control group. Like our study the difference in mortality was not statistically significant in both the above studies. The duration of hospital stay was also unaltered between IVIG and control group in Bangalore study.

The advantage of our study is that it was conducted in a setting of high mortality whereas the other two studies were conducted in the corporate hospitals of low mortality. In my study we included only preterm babies with $\leq 32$ wks. or low birth weight of $\leq 2000 \mathrm{gms}$ whereas the other two studies have included all gestational age and weight groups. Present study was conducted in a single unit over a short period so that the whole project was supervised by the same physician and assisted by the same team of nurses and residents. But the Bangalore study 
Sekar M.N et al. Randomized Control Trial of IVIG as An Adjuvant in the Treatment of Preterm and or Low Birth Weight Neonatal Sepsis.

\begin{tabular}{|c|c|c|c|c|c|c|}
\hline \multicolumn{9}{|c|}{ COMPARISON WITH OTHER STUDIES } \\
\hline & $\begin{array}{c}\text { Our Study } \\
\mathrm{n}=\mathbf{3 0}\end{array}$ & $\begin{array}{c}\text { Bangalore study } \\
\mathrm{n}=\mathbf{2 5}\end{array}$ & $\begin{array}{c}\text { TN Medical College } \\
\mathrm{n}=92\end{array}$ & $\begin{array}{c}\text { Our Study } \\
\mathrm{n}=30\end{array}$ & $\begin{array}{c}\text { Bangalore study } \\
\mathrm{n}=\mathbf{2 5}\end{array}$ & $\begin{array}{c}\text { TN Medical College } \\
\mathrm{n}=92\end{array}$ \\
\hline $\begin{array}{c}\text { Duration of hospital stay } \\
\text { in days (mean } \pm \text { sd) }\end{array}$ & $9.81 \pm 4.25$ & $17.0 \pm 2.08$ & - & $9.92 \pm 3.71$ & $18.3 \pm 2.34$ & - \\
\hline Mortality (\%) & $14(46.66)$ & $7(28)$ & $36(39.1)$ & $17(56.66)$ & $7(28)$ & $14(32.5)$ \\
\hline
\end{tabular}

was conducted as a multicentric study in 3 different hospitals and Mumbai study was conducted over a prolonged period of 2 years. The high mortality in our study is because of Enrolment of preterm babies and / or low birth weight babies only, the place of the study as it was conducted in the Government setup. Overcrowding of babies in NICU and under staffing.

\section{CONCLUSION}

In our study there is no significant decrease in mortality, severity of illness and duration of hospital stay in IVIG group than control group. As of other studies, our study also did not show any significant role of IVIG as an adjuvant in the treatment of sepsis in preterm or low birth weight neonates.

\section{REFERENCES}

[1]. Neonatal sepsis: Based on the proceedings of a single theme workshop on neonatal sepsis February 2002 PGIM ER. Chandigarh.

[2]. Kurien Anil Kuruvilla, Swathi Pillai. Bacterial profile of sepsis in a neonatal unit in South India. Indian Paediatrics Volume 35:Sep.1998:851-858.

[3]. M ehrban Singh, Care of the newborn, $5^{\text {th }}$ ed. Current status of perinatal care in India. Pg. 16-17.

[4]. Kavitha Bhola et al. Clinico-pathologcial profile of culture positive neonatal septicemia. Published in the XXIII convention of the National Neonatology Forum. Page. 1.

[5]. Barbara. J. Stoll. Nellie Hansen. Late onset of sepsis in very low birth weight neonates. The experience of NICHD neonatal Research Network. Paediatrics 2002;110(2):285-290.

[6]. W.H.O 1995 - Bridging the gaps. 1995 WHO report of the Director General.

[7]. Report of the National Seminar on traditional practices in mother and child care National Institute of public co-operation and child development, New Delhi 1989.

[8]. M ahapatra S.S., Baag, R.K : Customs and beliefs on neonatal care in a tribal community. Ind. Paediatrics. 1982;19:675-8.

[9]. Imad. R. Makhoul, Polo Sujov. Epidemiological, clinical and microbiological characteristics of late onset sepsis among very low birth weight infants in Israel. A National survey. Paediatrics 2002;109(II):34-6.
[10]. Nelson textbook of Paediatrics, $17^{\text {th }}$ ed. Saunders, Richard Bergman. Robert. M.Kliegman, Hall. B. Janson.

[11]. Weisman LE, Stoll BJ, Kenser TJ et al. IVIG therapy for early onset sepsis in premature neonates. J. Pediat. 1992;121:434-43.

[12]. Christenson KK, Christenson P, Bucher HV, et al. IV administration of human IgG to newborn Infants. Changes in serum antibody levels to group B streptococci Eur. J. Pediatr.1984;143:123-127.

[13]. Friedman CA. Wender DF, Temple DM , et al. IVIG as adjuvant therapy for severe Group B streptococcal disease in NB. Am. J. Perinatol 1990;7:1-4.

[14]. Haque KN, Zadir MH, Haque SK et al. IVIG for prevention of PT sepsis, Pediatr. Inf. Dis. 1986;5:622-5.

[15]. De Muralt G, Sidiroplous D. Replacement therapy with Ig in neonatology, Presse M ed. 1983;12:2595602.

[16]. Jenson AB, Pollock BH. The role of IVIG for prevention and treatment of NN sepsis. Semin Perinatol. 1998;22:50-63.

[17]. Kinney J, M undorf L, Gleason C et al. Efficacy and Pharmacokinetics of IVIG admn to high risk neonates. AJOC 1991;145:1233-38.

[18]. Fanaroff AA. Korones SB, Wright LLet al. A controlled trial of IVIG to reduced nosocomial infection in VLBW infant. N. Eng. J. Med. 1994;330:1107-13.

[19]. Magay JF, Oury CB, Brautt D, et al. IVIG therapy for prevention of infection in high risk premature infants - Reports of a multicenter double blind study. Paediatrics 1991;88: 437-42.

[20]. Chirico G, Rondini G. Plebani A et al. IVIG therapy for prophylaxis of infection in high risk neonates. J. Pediatri. 1987;110:437 - 42.

[21]. Canway SP, Gilles DRN, Dochety A. NN infection in premature infants and use of human Ig. Arch. Dis. Child. 1987;62:1255-56.

[22]. Stabile A, Sopo SM. Romanelli V, et al IVIG for prophylaxis of NN sepsis in premature infants. Arch. Dis. Child 1988;63:441-43.

[23]. Mankarious S Lee M, Fisher S, Pyun KK, Ochs HD et al. The half lives of IgG subclasses and specific antibodies in patients of primary immunodeficiency who are receiving IVIG. J.Lab. Clin. Med. 1988;112:634-640.

[24]. Michael D. Weiss, David J. Burchfield. Adjunct Therapies to Bacterial Sepsis in the Neonate NAINR. 2004;4(1).

\footnotetext{
How to cite this article: Sekar M.N, Anjan Kumar VS,

Ravi Kumar P, Siva Ramudu K, Mallikarjuna M, Sasi Kumar B. Randomized Control Trial of IVIG as An Adjuvant in the Treatment of Preterm and or Low Birth Weight Neonatal Sepsis. Int J Intg Med Sci 2015;2(5):115-120. Dol: 10.16965/ijims.2015.115
} 